\title{
The Big Data Development Direction of Modern Counting Computerization
}

\author{
Yahan Luo ${ }^{1, a^{*}}$, Yongmin Jiang ${ }^{2, b}$ \\ ${ }^{1}$ Dept.of finance and economics, Chengdu Polytechnic college, Chengdu, China \\ ${ }^{2}$ College of Electro-mechanical Engineering, Chengdu Technology University, Chengdu, China \\ a583401721@qq.com, bjym0408@126.com,
}

Keywords: Accounting information system; Accounting information platform; Big data Intelligent; Three-dimensional dynamic; Accounting management system.

\begin{abstract}
In order to promote the development of computerized accounting, the problems existing in the current is researched. By the way to use of big data, a solution is put forward. Based on cloud computing, the advent of the era of big data is deeply affected the human production and life. In today's world, who has the knowledge resources, he will walks in the forefront of The Times. The advent of the era of big data will give the accounting field bring enormous impact and challenges. Accounting function should expand and upgrade: three-dimensional dynamic reflect, process control, information resources integration, value creation management. Proposed in this paper, the structure of the intelligent three-dimensional dynamic accounting information platform and application, solve the problem of the existing accounting computerization. It will give a new way for the development of accounting computerization, meeting the needs of the economic development of the information.
\end{abstract}

\section{Introduction}

Big data lead future prosperity, provides a new direction for the development of accounting computerization. The role of accounting is to provide the economic activities of accounting and supervision of information. Traditional accounting subject is limited, the information flow is not big, can not fully reflect the state of economic activity. The development of The Times, update methods, increase traffic, it is necessary to sort out the problems existing in the accounting computerization, explore the method of using big data promote the development of accounting computerization.

Tiansheng Shi, mainly is a lot of units for the understanding of the accounting computerization is not comprehensive, accounting software, accounting computerized data security, keeping accounting files and the defects, etc.Woo ping road, square, this paper discusses the new era of big data the basic theoretical connotation and mode of scientific research method, is put forward under the information resources integration and technology integration of new scientific research method, realize the comprehensive utilization of information, the multidisciplinary integration. Han mei, what are the characteristics of big data in the field of economy how to better understanding, understanding, mastering and use of big data. Wang Gubin, and puts forward some ideas of accounting and business information and effective use. Big data just emerging, although the domestic and foreign scholars have done a lot of research, but the application in the field of accounting computerization has been lacking.

Accounting function should expand and upgrade: three-dimensional dynamic reflect, process control, information resources integration, value creation management. According to the large data processing technology, research "accounting wise", from "accounting data", starting from the definition of accounting information system, studies the structure of the intelligent three-dimensional dynamic accounting information platform and application, to solve the existing problem of accounting computerization. 
Research on new intelligent three-dimensional dynamic accounting information platform, through the system implementation including shorten reaction time, complex problem probing new ideas and insights, try out different strategies and enhance the effect of management control, reduce costs, objective decision-making, a variety of functions, in order to meet the needs of the accounting data mining.

The ultimate goal of the accounting information system will no longer be confined to provide accounting statements, but for the enterprise internal and external stakeholders provides different levels and different types of information.

\section{The Status Of The Computerized Accounting At This Stage}

The accounting computerization's current situation. Our country's accounting computerization used time is late, began in the late $80 \mathrm{~s}$ and early $1970 \mathrm{~s}$, after 20 years of development, our country's accounting computerization career has made gratifying achievements, the financial accounting software is developed in the commercialization brand. China has initially formed a accounting software industry through the national review of accounting software has amounted to more than 30 , through the provincial audit accounting software has more than 200.

Accounting computerization development up to now, is no longer just a simple combination of accounting and computer, but has developed into an extended to communication study, enterprise management, market operations research and so on comprehensive disciplines; Its application is no longer the pure financial management system, but is in the direction of the enterprise resource planning management system (ERP) development, and even develop into a trans-regional, cross-industry link each other between different enterprises of large network accounting information processing system, the effects of the deep is incalculable.

The Accounting Computerization's Current Situation. Accounting computerization existing problems at present stage

1. The accounting information system for not timely to provide more relevant decision-making information from all aspects of the criticism.If not carried out in accordance with the information technology reshape accounting industry, is likely to be pushed to the side, even by another industry, by providing information, analysis, verification, service industry has been replaced with a more innovative view ". Just think, when the enterprise is no longer as the only accounting information system, if the accounting information system can not provide the required information, policy makers will turn to other information subsystem. Reforming traditional accounting process, refactoring accounting information system is to adapt to changes in management, technology and demand of accounting information inevitably choice (Guo Linyan, 2006).

Wang qiang (2007) argue that the existing in the current accounting information system of the high redundancy information, sharing degree, poor security, high, narrow range, defects such as feedback lag.Yang Zhouna (2009) also pointed out that the current accounting information system acquisition and processing in the organization only part of the business events and the accounting information, the system output information content is limited.In view of the main problems of accounting informationization development in China, GaoBaoPing (2008) from the accounting information popularization application ability is not strong, poor financial software system internal cohesion, accounting software, poor universality, low level of integration, applicability of information-based accountant lending attributes, "against the invoicing, billing, cancel review" of the feasibility.

2. Accounting personnel's quality is low. The first performance in the accounting personnel is not complete and knowledge. Side and mainly concentrated in two parties: the old accounting personnel proficient in business accounting, the accounting work has a very rich experience, but to understand computer technology co., LTD, not familiar with;A new generation of accounting personnel is on the 
contrary, they can master the computer technology, but lack of experience in accounting work, cannot be skilled to complete accounting work.

Second is the computer training materials aging. The computer technology rapid development of modern society, carved, qualitative changes have taken place in a computer software company is a training with carved a computer teaching material is not suitable for JiXun. And around the accounting computerization training are too few formalism, not pragmatic, targeted content is poor, often don't get the desired effect, and high charge dampened the enthusiasm of accounting personnel computerized accounting knowledge.

3. Safety problems. With the rapid development of network, the security problems of the computerized accounting work more and more conspicuous, such as:

First, the network security problems.With the rapid development of modern computer network technology, computer network security becomes more and more attention, personally think that one of the most attention from the society of illegal invasion of criminals to the corporate Intranet via the Internet and sabotage, is one of the most serious of computer crime "hackers".A computer virus is also cannot ignore one of them, it is spreading at an alarming rate, threatening the safety of the computer system.

Second, the "paperless" risk.In manual accounting environment, enterprise's economic business will record in the paper, the data is modified, is it is easy to can be identified;But in computerized accounting, the data was recorded directly on disk or cd-rom, can modify a trace of data, the data storage way may lead to more risk.

Third, the data security isn't doing a good job.Financial data is absolutely secret, but software developers are now studying how to perfect the function of accounting software, few serious study data secrecy.For example, a company in Chengdu were stolen, one million yuan worth of data in the computer memory without any encryption and preventive measures, the company's loss is more than the value of the computer body. And some software encryption function, but it can't really play the data encryption function has a secret.

4. Lack of accounting software compatibility.First, the accounting information sharing is poor.Within the enterprise, with different departments each of the software of management activities, leading to the financial department and other departments communication is slow, cannot update and sharing all kinds of data, caused great waste of manpower and financial resources, more serious is to increase the data error rate, reduces the effectiveness of accounting information.

Second, the accounting software using standard parties, such as the chaos.As a result of the financial software development $\mathrm{m}$ can be unified standard, makes the financial software used in the accounting computerization is confusion, even in the same units of different software used are not the same.And different financial software data interface, the method of use is different, caused the report summary, data query, data transfer is not convenient.

Third, the versatility of weak accounting software, integration degree is not high.Financial software vendors to consider characteristics of the accounting industry and unit is not clear, not according to different type and size of the user to develop software to meet their characteristics, make a lot of units still need to do most of the auxiliary work, lack of practicability, and cannot be for data exchange, information sharing and management control, it is difficult to form the entire enterprise management information system.

Promote the accounting computerization. 1. To speed up the popularization of computerized.First of all, update, change ideas.In the process of computerized accounting, computerized accounting work carefully, and clearly the significance, sets up the accounting personnel as the core of humanistic thought.Specifically is importance to the role of the people, in particular, the role of accounting personnel, to firmly establish a man is the decisive factors in the accounting computerization this view. 
Second,the publicity of the accounting computerization, increase the intensity of support.To make the unit leadership change concept, the function and significance of the publicity of the accounting computerization, create a good atmosphere, let them know that the accounting computerization publication units in order to maximize economic benefits.Also strengthen unit the leadership of the modern consciousness, make its can be in hardware and software updates, personnel training and increase the intensity of support, meet the demand of the development of accounting computerization.

2. Actively training of computerized accounting need talent.One reason is to promote the development of accounting computerization training needed by the accounting computerization talent, so I think we can take the following measures:

First of all, the cultivation of accounting talents.In order to adapt to the demand of the development of computerized accounting, financial personnel should not only master the solid accounting knowledge and skills, and also dealing with financial management and computer knowledge have a more profound understanding. Therefore, in the process of accounting computerization, should cultivate "accounting, computer, management" model of compound talents, to promote the normal development of the accounting computerization.

Second, reduce the cost of training. One of the major problems of computerized accounting is talent problem, therefore the accounting personnel training is one of the necessary steps to implement computerization. And reduce the training costs can attract more accounting personnel to participate in the training of accounting computerization talent cultivation has been greatly enhanced, accounting personnel's professional quality has been greatly improved.

3. The problem of taking active measures to eliminate potential safety hazard. With the development of the network, I think you can take to measures, to prevent the problems of potential safety hazard: first, enhance the capacity of network security.Network accounting in the implementation of the accounting information resources sharing at the same time will also be their exposure to risk.In order to improve the security of network capacity, active measures should be taken, such as the firewall technology, network antivirus, information encryption storage communication, authentication, authorization, etc.

Second, to eliminate the risk generated by the "paperless".In view of the "paperless" the causes of risks, I think we should strengthen the file management of magnetic medium carrier.The paper archives and the archives new carrier double set of custody, and gradually transition to a completely takes care of the new type of magnetic medium carrier.

Third, to strengthen the data confidentiality and protection. When enter the system to add some protection measures, such as user password, detection means such as voice monitoring, the purport to identify and user permissions and other restrictions, to protect the data.Can also consider hardware encryption and software dog or do system on a chip machine confidentiality measures such as encryption, and formulate special management system, such as special special, special dedicated room, etc.

4. Solve the problem of accounting software is not compatible.First, the increase of accounting information sharing.I think that to increase the contact information, the accounting information and other departments use the same accounting software will do to less, so that you can avoid the waste because of the slow communication. We can also increase the intensity of the development of software, the software developed is suitable for the company's business characteristics, to meet their requirements.

Second, the establishment of a unified standard accounting software agreement. This agreement may be the same rules when using accounting software data interface, or regulations of public conversion interface, can make the different data transformation, data under different software systems that can be used directly, without further processing, so can reduce the operator's outfit, also published a potential according to different system working. 
Third, the accounting software should be gradually transition to the management direction, to form the core of enterprise management.To speed up the pace of development and management of accounting software, and financial software. Touch is an organic whole, whole and realize the accounting computerization, causing accounting computerization is accounting mode into management mode.Promote the popularization and application of management accounting in the enterprise, realize the accounting of the accounting function, management function and control function.The development of management information system for the enterprise to lay the solid foundation..

\section{Big Data Research Application In The Field Of Economic Analysis}

Big data to promote financial innovation. We all know that the collection of data about financial business has great influence on cost control, risk control, the application of large data can effectively promote the innovation of the Internet financial.

Through the analysis of trade big data effectively, so as to identify the market transaction pattern, and helping decision makers develop efficient arbitrage strategy.Through the social network market big data information analysis, and to focus on the hot point in the search engine, can also be quickly and efficiently develop investment strategy.And big data can daily trading behavior data analysis for the small and medium-sized enterprises, can judge the financial management system is not sound corporate management condition and credit conditions.

Big data effectively promote the resource optimization. Applied in the Internet financial data, can effectively promote the optimal allocation of resources.Internet can promote investment and financing information release, exchange and matching between the two sides, without the need for banking, securities, funds and other departments involved in.For example, the American Lending Club in loan business for our company, is the use of P2P platform, not through the banking institutions;Google is using the online method of Dutch auction, also does not have the use of traditional investment banking roadshow, inquiry offer for auction.In recent years, domestic also emerged a large number of P2P platform, the platform both Banks to participate in project financing, loans are financial information service enterprises formed network platform, pointed out the direction of the platform for small and medium-sized enterprise financing, also provides investors with low cost, high income of investment channels.Big data can effectively integrate the Internet financial resources, provide financial markets with a quick and efficient operating platform, the development of the Internet financial has a very important role.

Big data in the field of e-commerce applications. Big data of electronic commerce based on the cloud.Cloud technology, the information technology, management platform integrating technology, big data, and form a vast pool of resources, flexible and convenient to use as needed.In taobao, taobao cloud storage systems, for example, taobao as the nation's largest Internet shopping platform, orders, trading, shopping hobbies, commodity characteristics is the core of the business behavior of sellers and buyers data, structured is the characteristic of the data.Taobao cloud storage system as the relational cloud storage system, to meet the growing data level and storage, operation requirements, taobao cloud storage system database support, including evaluation of favorites, day cat, a number of important business data storage, and these data can be analyzed consumer shopping tendencies, so as to provide a more accurate recommend services to shoppers.And these are the large data of cloud technology based on the core application results.

Electricity is now an almost to the heated competition of industry.Each big electric business enterprise to win in the competition, you need to the whole enterprise of comprehensive data analysis, the application of large data is very important.Big data has large capacity, comprehensive, characteristics of structured data, by applying the technology of data, the enterprise can not only learn 
the most comprehensive data and information, more can through the data to master the latest development of the industry, provide guarantee for their victory.

Large data application in manufacturing industry. On manufacturing design, can use big data analysis of consumer comprehensive tendency, will the results of fast into the product design.General, in the field of high-end manufacturing, also need to have a design parameters such as the accumulation of data and applications. Of the same material to product, some can durable 10 years, some with broken in a few years, is this why? The main difference is the ratio of raw materials, processing, and technique, this is about to rely on many years of accumulation of data to form the large data.Manufacturing enterprises in the process of design, with large data of concept and technology, the manufacturing process from beginning to end for data capture, and feedback to the designers and technicians, so as to design better products and processes, to create better products, to obtain more economic benefits.For example, in fact, have a high degree of the current domestic high-end manufacturing automation and information technology, production line of machine tools

Basic it is automated, from raw materials into the plant to the finished product produce, people even don't have to intervene.Each nc machine tool is a small computer, a production line down and there are dozens of quality control points, a boot, as long as the machine can produce a huge amount of data per minute.Big data is vital for the manufacturing enterprises, can start from the first place, the data collected from the machine in its own dimension, knot again

Pre-built model, and gradually form the application of large data.Through the accumulation of a month, half a year, a year, you can analyze what factors related with quality, on this basis to improve products and production process.If there are many factories in the country, production is bigger, the big data of manufacturing enterprise itself is a standard application scenario.

For such a big data technologies used in industry, can produce huge economic benefits, enhance industry efficiency and benefits.

\section{Conclusion}

1) the concept of big data is a new word, some sure its role, also some people question its scientific nature and the significance, however, it must have the rationality of its existence.

2) the big data applications has great economic value, the most important part of the change in the economic field, that everyone's life is the most close economic.

3 ) if the full advantage of the large data to study the various problems in the economy, is bound to have a big innovation and results, will be helpful to the development of the economy.

4) A lot of accounting information and business data integration and sharing, it is help to analysis the decision related information. It is help the state administrative department to control economic information, to regulate economics, to serve the society. For enterprises to grasp business opportunities, improve market competitiveness.

\section{Acknowledgment}

The authors greatly appreciate the following sponsors for their support to the study: The natural science foundation of Science and Technology Agency of Sichuan province, (2014FZ0112).

\section{References}

[1] He Quanxiu.Data Management for Enterprise Group Accounting Information System under Internet Environment. 2008 International Conference of Management Science and Engineering .

[2] Shao Dan.From Accounting Computerlization to Modern Accounting Information System.China Management Informationlization . 2006 
[3] Zangxiu Qing, He Yufen.Technology security and defense of network accounting. Ccounting communications . 2009

[4] Shan Binglei.The Security-risks and prevention of Network Accounting Information sytem.

[5] Chinese Enterprise Accounting of Villages and towns . 2009

[6] Jian Wang, Li Yuting. Introduction to the role of accounting information age change [J]. Journal of accounting, 2010 (10)

[7] Ren Fuhai [2]. The problems existing in the accounting computerization and the improvement measures [J]. Friends of the accounting, 2004 (10) : P23-26

[8] Liqing, Xiangming Liu, the depth of the financial and business integration [J], commercial value, 2010.12: 